\title{
Ageing, retirement and changes in vegetable consumption in France: findings from the prospective GAZEL cohort
}

\author{
Marie Plessz ${ }^{1,2 *}$, Alice Guéguen ${ }^{2}$, Marcel Goldberg, ${ }^{2,3}$, Sébastien Czernichow ${ }^{2,3,4}$ and Marie Zins ${ }^{2,3}$ \\ ${ }^{1}$ UR1303 ALISS Alimentation et sciences sociales, INRA, 65 bd Brandebourg, 94205 Ivry sur Seine, France \\ ${ }^{2}$ Inserm, Population-based Epidemiologic Cohorts Unit, UMS 011, 12 Avenue Paul Vaillant Couturier, 94800 Villejuif, France \\ ${ }^{3}$ University of Versailles Saint Quentin, 55 Avenue de Paris, 78000 Versailles, France \\ ${ }^{4}$ Department of Nutrition, A. Paré Hospital, 9 Avenue Charles de Gaulle, 92100 Boulogne-Billancourt, France
}

(Submitted 4 July 2014 - Final revision received 11 February 2015 - Accepted 5 June 2015)

\section{Abstract}

The aim of this study was to describe the change in vegetable consumption with ageing and the transition to retirement. Study subjects were the participants of the GAZEL prospective cohort (Gaz and Électricité de France) aged 40-49 years at inclusion in 1989 who retired between 1991 and 2008 (12 942 men and 2739 women). Four FFQ were completed from 1990 to 2009. We used multiple imputation by chained equations in order to avoid dropping incomplete cases. The OR for eating vegetables everyday was estimated as a function of ageing, retirement status and the place of lunch before retirement through generalised estimating equations. Analyses were stratified by sex, and models were adjusted for confounders, including current spousal status. In 1990, $17 \cdot 7 \%$ of men and $31 \%$ of women reported eating vegetables daily. The odds of consuming vegetables everyday increased with ageing for both men and women. The usual place of lunch was home for less than half the sample before retirement and for almost every respondent after retirement. For those who changed their place of lunch, the association between being retired and the odds of eating vegetables daily was positive and significant. We found that, in this cohort, vegetable consumption increased with ageing. Retirement had an indirect effect on vegetable consumption mediated by changes in the place of lunch.

Key words: Ageing: Vegetable consumption: Retirement: Multiple imputations: Meal place: GAZEL prospective cohort

Vegetables are a major focus of current nutritional guidelines in developed countries because higher intakes can help protect from a wide range of non-communicable diseases ${ }^{(1)}$. Recent findings suggest that only $12 \%$ of the Americans meet the official dietary guidelines for vegetable intake ${ }^{(2)}$ and that the British consumed on average $135 \mathrm{~g} / \mathrm{d}$ of vegetables, $100 \mathrm{~g} / \mathrm{d}$ below the UK guidelines ${ }^{(3)}$. In France, vegetable intakes appear to be higher, close to the levels reported in Southern European countries $^{(4)}$, with $55 \%$ of the population eating more than two servings (160 g) daily ${ }^{(5)}$. Barriers to vegetable consumption include cost, poor nutritional knowledge and limited cooking time and skills ${ }^{(6-8)}$. Although people spend more time in food preparation in France than in many other European countries ${ }^{(9)}$, these factors are also associated with lower vegetable consumption $^{(5,10,11)}$

Cross-sectional surveys suggest a strong association between age and vegetable consumption in France and elsewhere ${ }^{(5,12-15)}$. However, it remains unclear whether age reflects the process of ageing, differences across birth cohorts or the impact of specific life-course transitions ${ }^{(16-19)}$ such as retirement. Studies on the transition to retirement have shown its positive impact on health outcomes such as self-rated health ${ }^{(20)}$ and sleep ${ }^{(21)}$, but results are unclear regarding physical activity ${ }^{(22,23)}$ or alcohol consumption $^{(24)}$. In a cohort of 1200 Finnish civil servants, Helldán et $a l^{(25)}$ found an increase in healthy food habits in retired women but not in retired men. Food budget tends to decline after retirement $^{(26)}$, along with a decline in eating out ${ }^{(27)}$ and an increase in time devoted to cooking ${ }^{(28)}$. However, adverse effects of retirement were also reported - for example, people who retired from strenuous jobs were found to gain weight and waist circumference while diminishing their fruit and vegetable intakes ${ }^{(29)}$. All these findings suggest that retirement might affect food consumption and especially vegetable consumption, but research on this aspect has been very limited thus far ${ }^{(30)}$.

The aim of this study was to assess the relative effects of both the ageing process and transition to retirement on the odds of daily vegetable consumption in a cohort with 19 years of follow-up.

\section{Methods}

Study design

The GAZEL cohort study (Gaz and Électricité de France) is an occupational cohort composed of 20625 employees of the

Abbreviation: GAZEL, Gaz and Électricité de France.

* Corresponding author: M. Plessz, fax +331 495969 90, email marie.plessz@ivry.inra.fr 


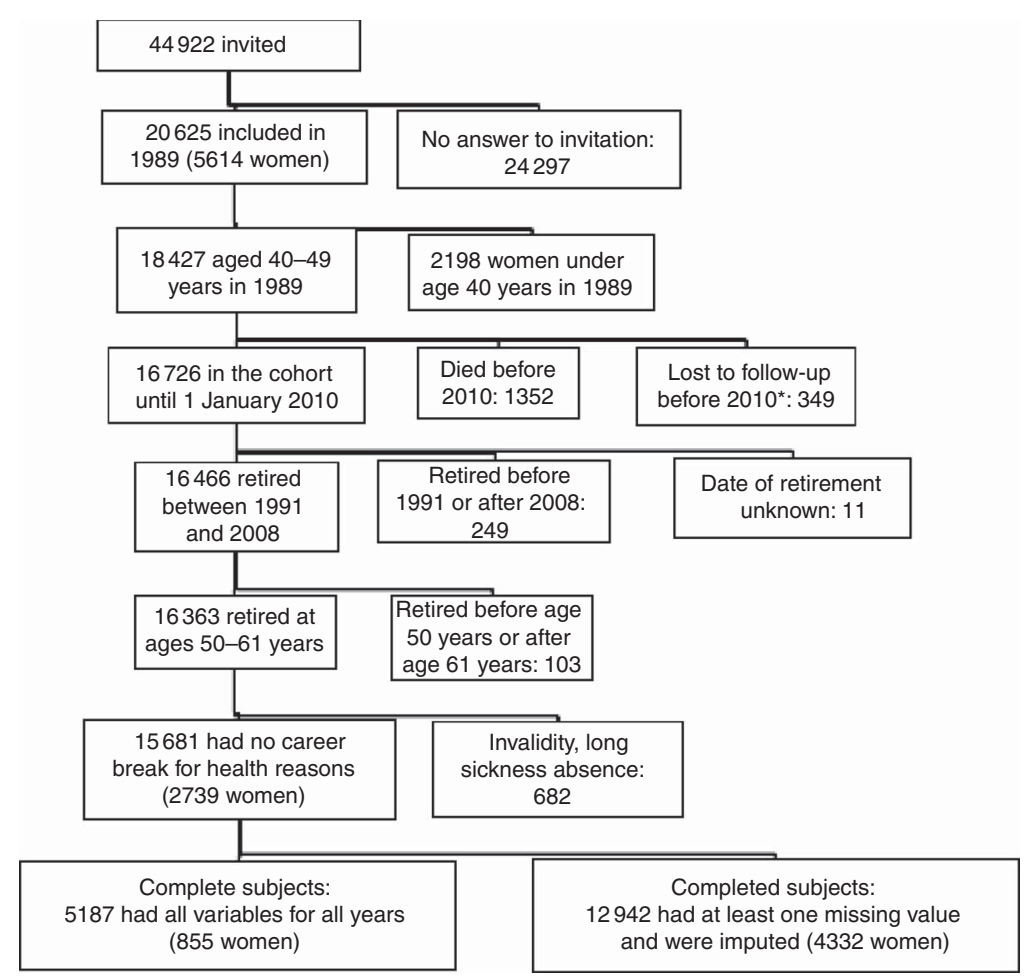

Fig. 1. Flowchart describing the selection of the study population from the GAZEL cohort, France 1989-2009. * Lost to follow-up: subjects asked not to be contacted again or stopped being employed by EDF-GDF before they retired.

French national Gas and Electricity Company, born in 19391948 (men) and 1939-1953 (women). The subjects were enrolled in 1989 and have been followed-up since then. Followup includes a mailed self-administered questionnaire every year; medical data from the medical department of the company; and linkage to the company's human resources database and to the national deaths registry, as described in detail elsewhere ${ }^{(31)}$. The company pays pensions to the retirees and provides mailing addresses to the investigators. For this reason, loss to follow-up was very low (see Fig. 1). A qualitative FFQ was included in the questionnaire in 1990, 1998, 2004 and 2009 ${ }^{(32)}$. The GAZEL study was approved by the National Commission overseeing ethics in data collection in France ('Commission Nationale Informatique et Liberté', CNIL, no. 105728).

\section{Population}

We selected individuals satisfying the following criteria: (a) aged 40-49 years in 1989 (birth years 1939-1948); (b) still alive at the end of 2009 (exclusion of 1352 deaths and 349 lost to follow-up); (c) retired after the first FFQ in 1990 and before the last FFQ in 2009; (d) aged between 50 and 61 years during retirement; (e) never had long-standing illness or disabilities, according to company records. This last restriction aimed at excluding individuals whose retirement was due to health issues.

\section{FFQ and outcome variable}

The qualitative FFQ was designed so as to capture eating habits (rather than nutritional intake). Subjects had to report how often they ate foods from various food groups over a typical week, from 'never' to 'daily or almost daily'(33). In 1990, the FFQ included ten food groups - for example, potatoes (fried, mashed) and green vegetables (fresh, canned or frozen). In 1998, the 'green vegetables' item was replaced by 'cooked vegetables as starter, soup or main dish (leeks, cabbage, green beans)' and 'crudités or raw vegetables (green salad, carrots, tomatoes, radish, beet)'. The FFQ did not change after 1998.

The outcome variable was defined as eating vegetables daily ( $v$. less than daily). In accordance with the French dietary guidelines, we did not include potatoes in the 'vegetables' group. We used the 'green vegetables' item in the 1990 FFQ and the 'cooked vegetables' item from the 1998 to the 2009 FFQ, because they appeared to be closest in content and distribution.

\section{Exposure variables}

The variables of interest were age in years and retirement status. For age, we used a piece-wise linear function with two knots at ages 50 and 61 years in order to capture non-linearities. Retirement status was coded using date of retirement as provided by company records.

\section{Mediator}

The impact of retirement on vegetable consumption could be mediated by a change in the usual place of lunch after retirement. The most frequent place for lunch (home $v$. away from home) was collected in the FFQ. We retained the most frequent place for lunch in the last FFQ before the subject's retirement. 


\section{Control variables}

All the analyses were stratified by sex.

The prevalence of diets followed for health reasons increased with age ${ }^{(5)}$. We controlled for whether the subject declared a diet prescribed by a doctor in each FFQ. Men living with a partner ate more vegetables ${ }^{(14,34,35)}$. Changes in spousal status or in the spouse's activity status may act as a confounder of the subject's retirement, and were therefore estimated at each FFQ year (no spouse, economically active spouse or inactive spouse).

In addition, we controlled for the birth cohort, coded in two categories (born between 1939 and 1943 or between 1944 and 1948). Educational level was coded in three categories: low (primary school or less, leaving school before age 12 years), medium (vocational or technical secondary education) or high (secondary school degree or higher education) ${ }^{(36)}$.

\section{Models}

In the first step, we modelled the outcome as a function of age, retirement status and the following potential confounders: date of FFQ (1990 v. 1998-2009), current status regarding doctorprescribed diet, birth cohort, education level and status of the spouse (model 1). In the second step, we studied whether a change in the usual place of lunch can mediate the association between retirement status and vegetable consumption. For this purpose, an interaction term between the place of lunch before retirement and retirement status was introduced (model 2).

We ran logistic regressions using generalised estimating equations (GEE) with an unstructured correlation matrix in order to account for the repetitive nature of the data.

In order to test whether the change in FFQ items affected the results, we estimated model 2, excluding the data from the year 1990.

\section{Treatment of missing data}

We imputed the non-responses using multiple imputation by chained equations ${ }^{(37,38)}$. This technique allows imputing missing information for several variables at a time, through an iterative process (the chained equations). Moreover, running multiple imputations produces between-imputation variance, which accounts for the precision or imprecision of the imputation process.

In the GAZEL study, non-response to the annual questionnaire was linked with sex, age, occupational status and retirement status, as well as with poor health and unhealthy lifestyle ${ }^{(39)}$. These variables had very high response rates because they were collected at inception in 1989 or from the company records (occupational status, retirement and age). They are also known predictors of vegetable consumption ${ }^{(5,12-14)}$. In order to account for the (assumed) non-response mechanism, the imputation model included the covariates from the model of interest as well as the following auxiliary variables: self-reported health at inclusion, smoking status at inclusion and occupational status at age 35 years (see online Supplementary materials for more details). Other auxiliary variables (BMI and alcohol consumption at baseline) were tested and discarded because they did not improve the quality of the imputations while creating collinearity issues.

We imputed the missing data separately for men and women. This allowed the imputation model to be fully compatible with the specifications of the model of interest. It also warranted that if the non-response mechanism or the sample size made the imputation less precise for women it would not affect the results for men. We generated fifty completed data sets, ran the GEE on these files and combined the results using Rubin's rules ${ }^{(40)}$, which take into account the variability in estimates and SE between the imputed data sets ${ }^{(38)}$. We also ran model 2 on the complete cases only (model 3). We carried out all the statistical analyses with Stata version 12 (commands 'mi impute chained' and 'mi estimate: gee'). Results are reported as odds ratios with $95 \%$ confidence intervals.

\section{Results}

\section{Study population}

Fig. 1 provides a flowchart for the selection of participants in the study. The population included 12942 men and 2739 women. Descriptive statistics and the number of missing values for men and women are presented in Table 1 (baseline characteristics) and Table 2 (time-varying variables). As the company has specific rules on retirement, retirement occurred on average at age 55 years. The average year of retirement was 1999 for men and 2000 for women. In the cohort, a higher

Table 1. Baseline characteristics: descriptive statistics and the number of missing values in men $(n 12942)$ and women $(n$ 2739) in the GAZEL cohort, France 1989-2009

(Percentages or mean values and standard deviations)

\begin{tabular}{|c|c|c|c|c|}
\hline & \multicolumn{2}{|c|}{ Men } & \multicolumn{2}{|c|}{ Women } \\
\hline & $\begin{array}{l}\text { Column } \\
\%^{*}\end{array}$ & $\begin{array}{l}\text { Number of } \\
\text { missing }\end{array}$ & $\begin{array}{l}\text { Column } \\
\%^{*}\end{array}$ & $\begin{array}{c}\text { Number of } \\
\text { missing }\end{array}$ \\
\hline Educational level† & & 238 & & 85 \\
\hline Low & $18 \cdot 9$ & & 31.9 & \\
\hline Medium & 53.4 & & 51.9 & \\
\hline High & $27 \cdot 7$ & & $16 \cdot 2$ & \\
\hline Birth cohort & & 0 & & 0 \\
\hline 1939-1943 & 41.4 & & $40 \cdot 1$ & \\
\hline 1944-1948 & $58 \cdot 6$ & & 59.9 & \\
\hline $\begin{array}{l}\text { Usual place of lunch } \\
\text { before retirement†‡ }\end{array}$ & & 2947 & & 772 \\
\hline Out & $53 \cdot 7$ & & $69 \cdot 9$ & \\
\hline Home & $46 \cdot 3$ & & $30 \cdot 1$ & \\
\hline Age in 1990 (years) & & & & \\
\hline $\begin{array}{l}\text { Mean } \\
\text { SD }\end{array}$ & $\begin{array}{r}45.9 \\
2.8\end{array}$ & 0 & $\begin{array}{r}45.9 \\
2.9\end{array}$ & 0 \\
\hline Year of retirement§ & & 0 & & 0 \\
\hline $\begin{array}{l}\text { Mean } \\
\text { SD }\end{array}$ & $\begin{array}{r}1999 \cdot 3 \\
3 \cdot 6\end{array}$ & & $\begin{array}{r}1999.9 \\
3.7\end{array}$ & \\
\hline $\begin{array}{l}\text { Age at the time of } \\
\text { retirement (years)§ }\end{array}$ & & 0 & & 0 \\
\hline Mean & 54.9 & & $55 \cdot 5$ & \\
\hline SD & $2 \cdot 4$ & & $2 \cdot 7$ & \\
\hline
\end{tabular}

* Column percentages based on available cases for the categorical variables (pairwise deletion). Mean and standard deviation for the continuous variables. $\dagger$ Difference between men and women statistically significant $\left(X^{2}\right.$ test: $\left.P<0.001\right)$. $\ddagger$ Measured at the last FFQ before retirement.

$\S$ Difference between men and women statistically significant ( $t$ test: $P<0.001$ ). 
Table 2. Sample characteristics: descriptive statistics and the number of missing values for the variables with repeated measurements for men ( $n$ 12 942 ) and women ( $n$ 2739) in the GAZEL cohort, France 1989-2009*

\begin{tabular}{|c|c|c|c|c|c|c|c|c|}
\hline & \multicolumn{4}{|c|}{ Men } & \multicolumn{4}{|c|}{ Women } \\
\hline & 1990 & 1998 & 2004 & 2009 & 1990 & 1998 & 2004 & 2009 \\
\hline \multicolumn{9}{|c|}{ Outcome: daily consumption of vegetables $\dagger$} \\
\hline Yes (\%) & $17 \cdot 7$ & 19.9 & 28.6 & 33.4 & 31.0 & $36 \cdot 1$ & $50 \cdot 8$ & $55 \cdot 3$ \\
\hline Number of missing & 1616 & 3235 & 3050 & 3282 & 372 & 810 & 709 & 750 \\
\hline \multicolumn{9}{|l|}{ Spouse (column \%)† } \\
\hline No spouse & 6.4 & 7.7 & $9 \cdot 0$ & $10 \cdot 5$ & $21 \cdot 7$ & 24.9 & 26.5 & $29 \cdot 7$ \\
\hline Spouse works & $52 \cdot 5$ & $46 \cdot 3$ & $28 \cdot 1$ & $13 \cdot 0$ & $72 \cdot 5$ & 43.7 & $15 \cdot 4$ & 4.4 \\
\hline Spouse inactive & $41 \cdot 1$ & $46 \cdot 0$ & 62.9 & 76.5 & 5.7 & 31.4 & $58 \cdot 2$ & 65.9 \\
\hline Number of missing & 1555 & 3239 & 2941 & 3216 & 361 & 816 & 702 & 738 \\
\hline \multicolumn{9}{|c|}{ Diet prescribed by a doctor } \\
\hline Yes (\%) & $15 \cdot 8$ & 8.0 & 8.6 & 6.9 & $16 \cdot 3$ & $8 \cdot 3$ & 9.6 & 6.6 \\
\hline Number of missing & 1794 & 5443 & 4003 & 5117 & 454 & 1203 & 890 & 1136 \\
\hline
\end{tabular}

* Column percentages based on available cases (pair-wise deletion).

$\dagger$ Difference between men and women statistically significant each year $\left(P<0.001 ; x^{2}\right.$ test).
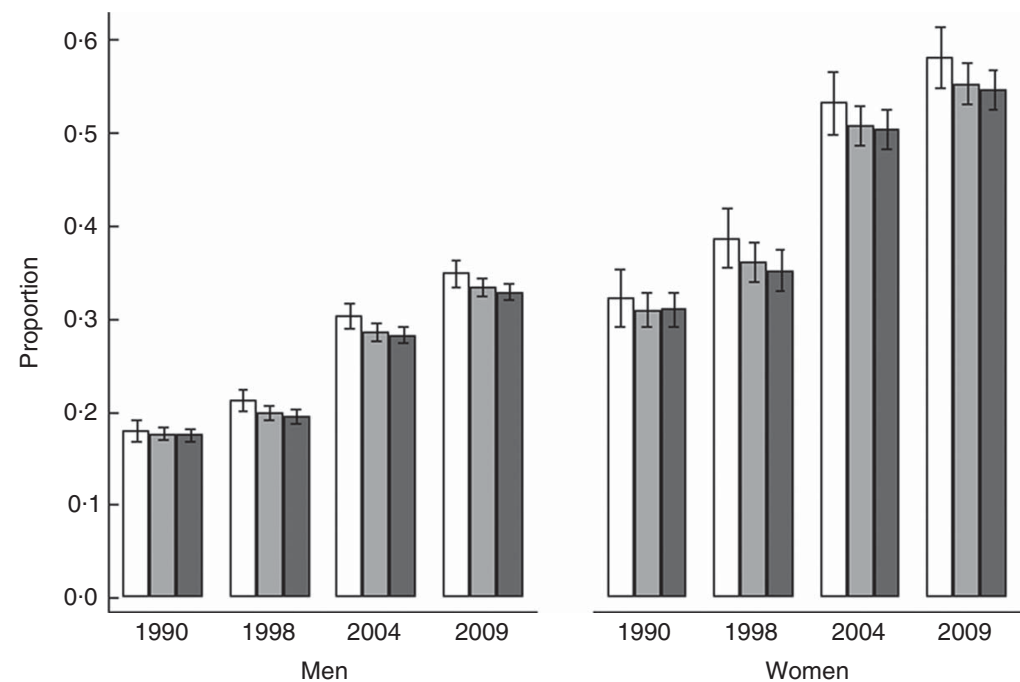

Fig. 2. Proportion of subjects eating vegetables daily according to sex and year of measurement among complete cases ( $\square$, list-wise deletion), available cases ( $\square$, pair-wise deletion) and after imputation $(\square)$ in the GAZEL cohort, France 1989-2009, with $95 \%$ confidence intervals represented by vertical bars. Imputed data: fifty imputed files, for details see the 'Methods' section.

proportion of women ate vegetables every day over the entire follow-up period, had a low educational level and were single $(P<0 \cdot 001)$. Among the available cases (respondents who completed the questionnaires in a given year), between 1990 and 2009, the daily consumption of vegetable increased from 17.7 to $33.4 \%$ for men and from 31 to $55.3 \%$ for women. The proportion of individuals without a spouse increased for both sexes. Crude associations between the repeated measurements of vegetable consumption are presented in the online Supplementary material.

\section{Missing values and imputation}

Only 4332 men and 855 women had no missing values (complete cases). The number of missing outcomes increased after 1990 (Table 2). Fig. 2 displays the proportion of subjects who declared that they ate vegetables everyday according to year of measurement for both sexes, among the complete cases (list-wise deletion), the available cases (pair-wise deletion) and after imputation (fifty completed data sets). The proportion of positive outcomes was lower after imputation than among the complete cases, and the gap widened over time, although CI overlap.

\section{Ageing and retirement}

Table 3 reports the OR of daily consumption of vegetables. Model 1 showed the evolution of vegetable consumption as the subjects grew older and retired, based on the imputed data. The odds of eating vegetables daily increased steadily by $6 \% /$ year of age for men (95\% CI 5, 7\%) and 7\% for women (95\% CI 4 , $10 \%)$ until age 61 years. After age 61 years, the increase was smaller but remained statistically significant.

Model 1 also showed that being retired had a positive and significant effect on the odds of eating vegetables every day for men, but the effect was not significant for women. For men, 
Table 3. Multivariate models for daily vegetable consumption, men and women in the GAZEL cohort, France 1989-2009 (Odds ratios* and $95 \%$ confidence intervals)

\begin{tabular}{|c|c|c|c|c|c|c|c|c|c|c|c|c|}
\hline & \multicolumn{6}{|c|}{ Men } & \multicolumn{6}{|c|}{ Women } \\
\hline & \multicolumn{2}{|c|}{ Model 1} & \multicolumn{2}{|c|}{ Model 2} & \multicolumn{2}{|c|}{ Model 3} & \multicolumn{2}{|c|}{ Model 1} & \multicolumn{2}{|c|}{ Model 2} & \multicolumn{2}{|c|}{ Model 3} \\
\hline & OR & $95 \% \mathrm{Cl}$ & OR & $95 \% \mathrm{Cl}$ & OR & $95 \% \mathrm{Cl}$ & OR & $95 \% \mathrm{Cl}$ & OR & $95 \% \mathrm{Cl}$ & OR & $95 \% \mathrm{Cl}$ \\
\hline Age: slope $42-50$ years & 1.06 & $1.04,1.08$ & 1.06 & $1.03,1.08$ & 1.08 & $1.05,1 \cdot 11$ & 1.08 & $1.04,1.11$ & 1.07 & $1.04,1 \cdot 11$ & $1 \cdot 1$ & $1.05,1.17$ \\
\hline Age: slope $50-61$ years & 1.06 & $1.05,1.07$ & 1.06 & $1.05,1.07$ & 1.07 & $1.05,1.09$ & 1.07 & $1.04,1 \cdot 10$ & 1.07 & $1.04,1 \cdot 10$ & 1.09 & $1.05,1.13$ \\
\hline Age: slope $61-70$ years & 1.03 & $1.02,1.05$ & 1.03 & $1.02,1.05$ & 1.03 & $1.01,1.04$ & 1.04 & $1.01,1.06$ & 1.04 & $1.01,1.06$ & 1.03 & $1.00,1.07$ \\
\hline $\begin{array}{l}\text { Retired } \\
\text { Red }\end{array}$ & $1 \cdot 19$ & $1.08,1.31$ & & & & & 1.16 & $0.97,1.39$ & & & & \\
\hline Not retired and lunches at home† & & & 1.28 & $1.18,1.39$ & 1.32 & $1.16,1.49$ & & & 1.16 & $0.99,1.35$ & 1.31 & $1.01,1.70$ \\
\hline Retired and lunched out† & & & 1.31 & $1.17,1.46$ & 1.25 & $1.07,1.46$ & & & 1.21 & $1.01,1.46$ & $1 \cdot 18$ & $0.89,1.56$ \\
\hline Retired and lunched at home $†$ & & & 1.38 & $1.23,1.54$ & 1.31 & $1.10,1.56$ & & & 1.22 & $0.97,1.53$ & 1.27 & $0.90,1.81$ \\
\hline FFQ 1990 (ref: 1998-2009) & 1.42 & $1.26,1.59$ & 1.41 & $1.26,1.58$ & 1.46 & $1.23,1.74$ & 1.44 & $1 \cdot 16,1 \cdot 78$ & 1.43 & $1 \cdot 16,1.77$ & 1.56 & $1 \cdot 13,2 \cdot 16$ \\
\hline Diet prescribed by a doctor & 1.29 & $1.19,1.41$ & 1.29 & $1 \cdot 19,1.41$ & 1.33 & $1.18,1.49$ & 1.7 & $1.46,1.99$ & 1.7 & $1.46,1.99$ & 1.59 & $1 \cdot 27,2 \cdot 00$ \\
\hline Born 1944-1948 (ref: 1939-1943) & 1.12 & $1.04,1.19$ & $1 \cdot 12$ & $1.05,1.19$ & $1 \cdot 11$ & $1.00,1.23$ & 1.3 & $1.13,1.48$ & 1.3 & $1.13,1.49$ & 1.58 & $1.26,1.97$ \\
\hline Education: medium (ref: low) & 1.15 & $1.06,1.25$ & 1.15 & $1.06,1.25$ & 1.14 & $1.01,1.29$ & 1.09 & $0.95,1.24$ & 1.09 & $0.96,1.24$ & 1.02 & $0.82,1.27$ \\
\hline Education: high & 1.21 & $1.11,1.32$ & 1.22 & $1.12,1.33$ & 1.14 & $0.99,1.31$ & 1.42 & $1.19,, 1.69$ & 1.43 & $1 \cdot 20,1 \cdot 70$ & 1.39 & $1.04,1.85$ \\
\hline Spouse works (ref: no spouse) & 1.35 & $1.21,1.50$ & 1.35 & $1.21,1.50$ & 1.43 & $1.20,1.69$ & 1.03 & $0.89,1 \cdot 18$ & 1.02 & $0.89,1.17$ & $1 \cdot 15$ & $0.91,1.46$ \\
\hline Spouse inactive & 1.62 & $1.47,1.79$ & 1.6 & $1.45,1.77$ & 1.74 & $1.48,2.06$ & 1.25 & $1.09,1.43$ & 1.25 & $1.09,1.43$ & 1.26 & $1.02,1.56$ \\
\hline Number of observations & 51768 & & 51768 & & 17328 & & 10956 & & 10956 & & 3420 & \\
\hline Number of subjects & 12942 & & 12942 & & 4332 & & 2739 & & 2739 & & 855 & \\
\hline
\end{tabular}

Model 1, controls + age + retirement status, completed data (fifty imputations); model 2, controls + age + interaction between retirement status and usual place of lunch before retirement, completed data (fifty imputations); model 3, same as model 2 on complete cases (list-wise deletion: subjects with zero missing value).

${ }^{*}$ Logistic regressions using generalised estimating equations.

$\dagger$ Lunch: the most frequent place of lunch declared at the last FFQ before retirement. Reference category: not retired and lunches out.

retiring was equivalent to being 3 years older in terms of vegetable consumption.

\section{Place of lunch before retirement}

Based on the available cases of our sample (pair-wise deletion), in the last FFQ before retirement, the most frequent place for lunch was away from home for $53.7 \%$ of men and $69.9 \%$ of women (Table 1). After retirement only $1.5 \%$ of the respondents had most lunches away from home, implying that most of those who used to lunch out started to lunch at home.

Model 2 in Table 3 shows that before retirement, men who had most of their lunches at home ate vegetables significantly more often than those who had lunch away from home (OR $1.28 ; 95 \%$ CI 1.18, 1.39). The difference was smaller and not significant for women (OR 1.16). After retirement, there was no significant difference between the subjects who used to have lunch away from home when working and those who did not.

Indeed, for men who had lunch mostly away from home before retirement, the effect of retirement was positive and statistically significant (OR 1.31; $95 \%$ CI 1.17, 1.46). For these men, getting retired increased the chances of daily vegetable consumption in the same proportions as being 5 years older. In contrast, those who had lunch mostly at home when working increased only slightly and non-significantly their vegetable intake upon retirement (before retirement OR 1.28 v. after retirement: 1.38). The same was true for women: those who used to lunch out increased their vegetable consumption after retirement (OR 1.21), whereas for the others the OR before and after retirement were very close $(1.16 v .1 .22)$.

Fig. 3 displays the results of model 2 as predicted probabilities of eating vegetables daily if the subjects had retired at age 56 years. In terms of probabilities of eating vegetables daily, the gap between men and women grew larger over time. The transition to retirement implied no change for those who had lunch at home at the end of their active life. There was a positive change for those who had lunch away from home before retirement, and after retirement the two groups did not differ in their vegetable consumption.

\section{Robustness checks}

In order to assess the impact of the imputation process on the results, we ran model 2 on the complete cases only (model 3 in Table 3). Changes in estimate values were modest and nonsignificant for men. Some coefficients varied more markedly for women, possibly due to the smaller number of complete cases.

In 1990, the question on vegetables was about 'green vegetables', whereas later on the item was 'cooked vegetables'. We tested whether this change affected the estimates by running model 2 on the imputed data after excluding the 1990 FFQ, and found very similar results (online Supplementary material).

\section{Discussion}

We used four FFQ over 19 years of follow-up to assess the evolution of vegetable consumption between ages 42 and 70 years, as subjects aged and retired. Our results show that for both men and women the process of ageing was associated with gradually increasing odds of eating vegetables every day. The increase in vegetable consumption observed upon the transition to retirement appeared to be mediated by the place of lunch before retirement. These results hold after imputing non-responses and taking into account the main potential confounders. 


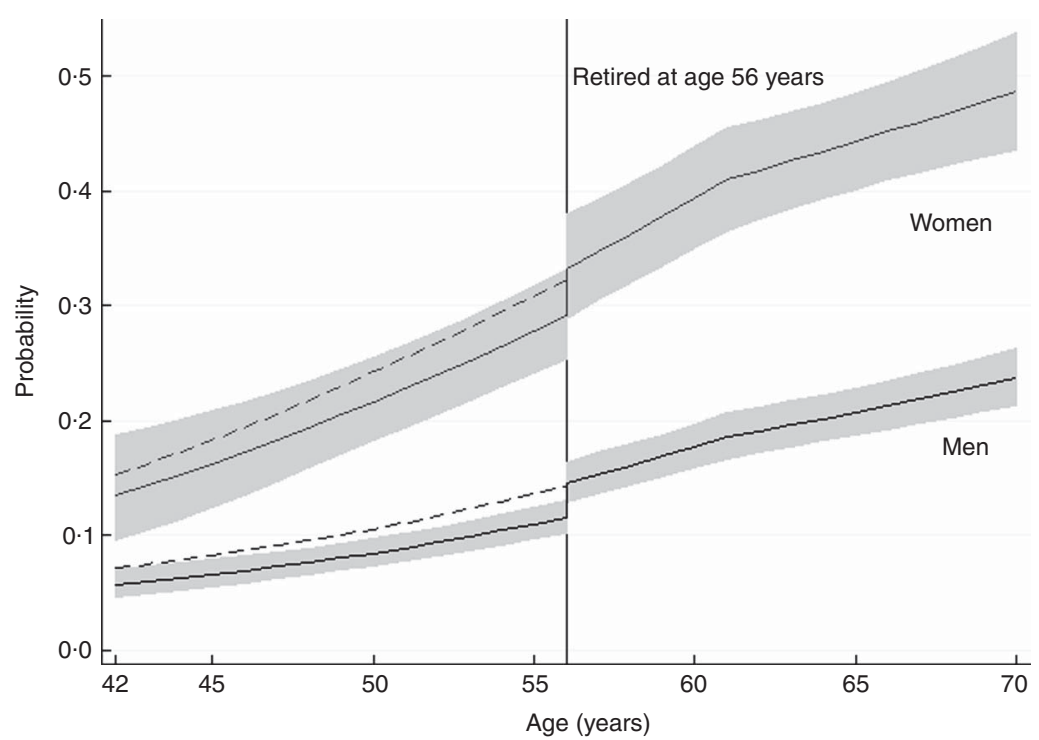

Fig. 3. Predicted probabilities of consuming vegetables daily for men and women according to age, retirement status and usual place of lunch before retirement in the GAZEL cohort, France 1989-2009. Predicted probabilities of eating vegetables everyday in the GAZEL cohort study are based on model 2 (imputed data), assuming that retirement occurred at age 56 years adjusted for educational level (high $v$. low), current doctor-prescribed dieting status (no $v$. yes), current marital status (no $v$. yes), FFQ 1998 or later. Solid line, predicted probability for people having most lunches away from home before retirement; shaded area, $95 \%$ confidence interval for the solid line; dashed line, before retirement, alternative prediction for a person who had most lunches at home.

Age is associated with increased vegetable consumption in cross-sectional studies ${ }^{(5,12-14)}$. Our study suggests that as a given birth cohort grows older, its members tend to eat vegetables more often. This ageing effect remains positive and significant after controlling for retirement status, but also for current spousal status, current dieting prescription status and birth cohort. The ageing effect is relatively stable over time, at least from 42 to 61 years of age, and may decline slightly afterwards.

Retirement is a major life-course transition between midlife and old age. Although the association between transition to retirement and changes in health-related behaviour such as alcohol drinking and physical activity have been studied before, there are only few studies on changes in food intake ${ }^{(25,30,41)}$. In this cohort study, retiring was associated with increased vegetable consumption in those respondents whose meal environment changed upon retirement. This is consistent with the life-course perspective on food consumption ${ }^{(16-19)}$.

Food eaten away from home seems to be less healthy than food eaten at home ${ }^{(42,43)}$. Evidence is less clear on the nutritional quality of meals consumed at work - for example, in staff or university canteens ${ }^{(44-46)}$. In France, a nationally representative survey including a 7 -d food diary found that $26 \%$ of the lunches eaten by adults were consumed away from home ${ }^{(47)}$. In the USA, a similar figure $(25 \%)$ was found in the NHANES survey 2003-2004 ${ }^{(42)}$. In our study, those who had lunch away from home while working ate vegetables less often, but vegetable consumption after retirement did not differ according to the place of lunch before retirement.

This result may be related to the impact of the spouse on male respondents' food habits. In the GAZEL study, men's BMI depended more on the spouse's social status than on the respondent's occupational category ${ }^{(48)}$. In the present study, the presence of a spouse was associated with higher odds of eating vegetables every day for males. Women's vegetable consumption was higher than men's and less affected by the presence of a spouse. This may be linked to the fact that women have better nutritional knowledge ${ }^{(8)}$ and do most of the cooking in European countries ${ }^{(49)}$.

Our hypothesis was that getting retired may have a causal effect on vegetable consumption, through changes in the place of lunch. In order to move from the measurement of an association to the identification of a causal pathway, we have taken several precautions. A reverse causality path from vegetable consumption to retirement was unlikely. We controlled for several sources of confusion, besides ageing. A poor health condition during active life could lead both to retiring earlier than expected and to adopting healthier eating habits, including higher vegetable consumption. We therefore excluded from the study population all individuals who had a long-standing illness or disability, according to the company records, and we controlled for current dieting prescription status. It is also necessary to separate the subject's retirement from his or her spouse's retirement: we controlled for the presence and the activity status of the spouse at each FFQ date. In addition, we controlled for birth cohort, education level and changes in the questionnaire.

Another potential source of confusion is the period of observation. Over $60 \%$ of the subjects retired between 1998 and 2004. In 2001, France launched nutrition information campaigns including the message to eat 'five fruits and vegetables a day'. According to cross-sectional surveys, the share of the adult population aware of this nutritional guideline $(2.5 \%$ in 2002) increased 11-fold between 2002 and 2008 ${ }^{(5)}$. However, based on the 24-h recalls included in the same surveys, the level of vegetable consumption had not changed much: the share of the French population who ate five fruit and vegetable servings 
a day was estimated to be $10 \cdot 2 \%$ in 2002 and $13 \%$ in $2008^{(5,50)}$. Confusion between the measured effect of ageing and the impact of nutrition information campaigns during the observation period might play a role, but it is very unlikely that it would explain all the ageing and retirement effects.

An important limitation regarding the interpretation of the results is the population included in the survey. Respondents were all employees of a large, state-owned French company. Although their social background was diverse (over $80 \%$ entered the firm as blue-collar or clerical workers $\left.{ }^{(31)}\right)$, the subjects' risk of being laid-off was virtually null and their income did not drop substantially after retirement. It is therefore likely that the impact of retirement would be lower in a population exposed to unemployment or having less protective retirement status. Similarly, it would be unwise to extend our conclusion to other age groups or birth cohorts than those included in this survey. Indeed, it appears that, in the GAZEL cohort, the subjects born after 1943 had a higher $\mathrm{BMI}^{(36)}$ and lower alcohol consumption ${ }^{(24)}$. Other studies in France suggest differences in lifestyle and food consumption across birth cohorts born after the Second World War ${ }^{51,52)}$. In addition, in the GAZEL cohort, men are far more numerous than women. Although the results seemed robust for men, for women it was sometimes unclear whether the estimates were non-significant because the associations were weaker or because the sample size reduced the power of the tests.

Measures of vegetable (or fruit) intake are sensitive to survey designs and definitions. For example, the French official dietary guideline of five fruits and vegetables a day is met by only $13 \%$ of the French population ${ }^{(5)}$, but around $45 \%$ of the French have intakes $\geq 400 \mathrm{~g} / \mathrm{d}^{(5,53,54)}$. In $2008,86 \%$ of the French respondents (aged 12-75 years) to a nutritional survey had eaten vegetables at least once during the $24-\mathrm{h}$ recall $^{(5)}$. In contrast, in our occupational cohort, in 2009, one out of three men and $55 \%$ of the women reported that they usually ate (cooked) vegetables every day. Rather than food intake, our short, qualitative and self-administered FFQ captured food habits namely, whether a food group is usually consumed on a daily basis. Misreporting is possible, but measurement error induces bias in a longitudinal analysis only if it is time-dependent. In our case, the FFQ did not change from 1998 to 2009. The FFQ changed between 1990 and 1998, but our robustness check showed that this did not affect our results. Measurement error should, therefore, not be a concern in this study. Finally, as we do not control for total food intake or BMI, it is possible that the subjects increased their consumption of unhealthy foods along with their vegetable consumption. Although our results indicate that vegetable consumption complied more and more with nutritional guidelines as subjects grew older, it remains to be shown whether their whole diet became healthier.

Major strengths of our study were a large sample size and a long follow-up period, with very low attrition: more than 16000 subjects were followed-up over 19 years, with four repeated questionnaires on their food habits. To our knowledge, there is no comparable study on vegetable consumption and ageing. Moreover, due to the initial recruitment of people aged over 40 years in a large, state-owned company, virtually every subject had a continuous work history in the company and had retired during the survey period. Multiple imputation of missing values prevented loss of power and reduced bias due to nonresponse. We were also able to address several potential sources of confusion.

In developed countries, people aged 60 years and above represent nearly $23 \%$ of the population. They face a life expectancy of 23 years at 60 years of age ${ }^{(55)}$, with an increasing risk of nutrition-related chronic diseases. Although population ageing is a major public health concern for industrialised societies, our results also suggest that ageing and retiring may have a positive effect on vegetable intake among older adults. This supports the idea that dietary interventions at the time of retirement may make an effective and sustainable ${ }^{(56)}$ contribution to healthy ageing.

\section{Supplementary material}

For supplementary material/s referred to in this article, please visit http://dx.doi.org/doi:10.1017/S0007114515002615

\section{Acknowledgements}

The authors thank EDF-GDF and the Population-based Epidemiologic Cohorts Unit (UMS 011 INSERM/UVSQ) for their contribution to building and providing the GAZEL database. The authors are grateful to Dr Séverine Gojard (INRA ALISS), Dr Éléonore Herquelot (INSERM UMS 011) and Diane Cyr (INSERM UMS 011) for their support and comments.

This research received no specific grant from any funding agency, commercial or not-for-profit sectors.

M. P., M. G., M. Z. and S. C. designed the research. M. P. and A. G. analysed the data. M. P. wrote the paper. M. Z. and M. G. provided detailed information on the data. All the authors revised the text and approved the final draft.

The authors declare no conflicts of interest.

\section{References}

1. World Health Organization (2003) WHO Fruit and Vegetable Promotion Initiative - A Meeting Report. Geneva: WHO.

2. Krebs-Smith SM, Guenther PM, Subar AF, et al. (2010) Americans do not meet federal dietary recommendations. J Nutr 140, 1832-1838.

3. Maguire ER \& Monsivais P (2015) Socio-economic dietary inequalities in UK adults: an updated picture of key food groups and nutrients from national surveillance data. Br J Nutr 113, 181-189.

4. Orfanos P, Naska A, Trichopoulos D, et al. (2007) Eating out of home and its correlates in 10 European countries. The European Prospective Investigation into Cancer and Nutrition (EPIC) study. Public Health Nutr 10, 1515-1525.

5. Escalon H, Bossard C and Beck F (2009) Baromètre santé nutrition 2008 (Health Nutrition Barometer 2008). SaintDenis: INPES.

6. Welch N, McNaughton SA, Hunter W, et al. (2009) Is the perception of time pressure a barrier to healthy eating and physical activity among women? Public Health Nutr 12, 888-895.

7. Crawford D, Ball K, Mishra G, et al. (2007) Which food-related behaviours are associated with healthier intakes of fruits and vegetables among women? Public Health Nutr 10, 256-265. 
8. Baker AH \& Wardle J (2003) Sex differences in fruit and vegetable intake in older adults. Appetite 40, 269-275.

9. Warde A, Cheng S-L, Olsen W, et al. (2007) Changes in the practice of eating. Acta Sociologica 50, 363-385.

10. Plessz M \& Gojard S (2015) Fresh is best? Social position, cooking, and vegetable consumption in France. Sociology 49 172-190.

11. Bertail P \& Caillavet F (2008) Fruit and vegetable consumption patterns: a segmentation approach. Am J Agri Econ 90 , 827-842.

12. Lindström M, Hanson BS, Wirfält E, et al. (2001) Socioeconomic differences in the consumption of vegetables, fruit and fruit juices. Eur J Public Health 11, 51-59.

13. Roos G, Johansson L, Kasmel A, et al. (2001) Disparities in vegetable and fruit consumption: European cases from the north to the south. Public Health Nutr 4, 35-43.

14. Plessz M \& Gojard S (2013) Do processed vegetables reduce the socio-economic differences in vegetable purchases? A study in France. Eur J Public Health 23, 747-752.

15. Dubuisson C, Lioret S, Touvier M, et al. (2010) Trends in food and nutritional intakes of French adults from 1999 to 2007: results from the INCA surveys. Br J Nutr 103, 1035-1048.

16. Devine CM, Connors M, Bisogni CA, et al. (1998) Life-course influences on fruit and vegetable trajectories: qualitative analysis of food choices. J Nutr Educ 30, 361-370.

17. Bisogni CA, Jastran M, Shen L, et al. (2005) A biographical study of food choice capacity: standards, circumstances, and food management skills. J Nutr Educ Behav 37, 284-291.

18. Furst T, Connors M, Bisogni CA, et al. (1996) Food choice: a conceptual model of the process. Appetite 26, 247-266.

19. Plessz M, Dubuisson-Quellier S, Gojard S, et al. (2014) How consumption prescriptions change food practices. Assessing the role of household resources and life course events. J Consum Cult (epublication ahead of print version 4 February 2014).

20. Westerlund H, Kivimäki M, Singh-Manoux A, et al. (2009) Selfrated health before and after retirement in France (GAZEL): a cohort study. Lancet 374, 1889-1896.

21. Vahtera J, Westerlund H, Hall M, et al. (2009) Effect of retirement on sleep disturbances: the GAZEL prospective cohort study. Sleep 32, 1459-1466.

22. Sjösten N, Kivimäki M, Singh-Manoux A, et al. (2012) Change in physical activity and weight in relation to retirement: the French GAZEL Cohort Study. BMJ Open 2, e000522.

23. Slingerland AS, van Lenthe FJ, Jukema JW, et al. (2007) Aging, retirement, and changes in physical activity: prospective cohort findings from the GLOBE study. Am J Epidemiol 165 1356-1363.

24. Zins M, Guéguen A, Kivimaki M, et al. (2011) Effect of retirement on alcohol consumption: longitudinal evidence from the French GAZEL cohort study. PLOS ONE 6, e26531.

25. Helldán A, Lallukka T, Rahkonen O, et al. (2012) Changes in healthy food habits after transition to old age retirement. Eur J Public Health 22, 582-586.

26. Hurd MD \& Rohwedder S (2006) Some answers to the retirement-consumption puzzle. NBER Working paper no. 13929. Cambridge, MA: National Bureau of Economic Research.

27. Chung S, Popkin BM, Domino ME, et al. (2007) Effect of retirement on eating out and weight change: an analysis of gender differences. Obesity 15, 1053-1060

28. Stancanelli E \& Soest AV (2012) Retirement and home production: a regression discontinuity approach. Am Econ Rev 102, 600-605.

29. Nooyens AC, Visscher TL, Schuit JA, et al. (2005) Effects of retirement on lifestyle in relation to changes in weight and waist circumference in Dutch men: a prospective study. Public Health Nutr 8, 1266-1274.

30. Zantinge EM, van den Berg M, Smit HtA, et al. (2014) Retirement and a healthy lifestyle: opportunity or pitfall? A narrative review of the literature. Eur J Public Health 24, 433-439.

31. Goldberg M, Leclerc A, Bonenfant S, et al. (2007) Cohort profile: the GAZEL Cohort Study. Int J Epidemiol 36, 32-39.

32. Le Port A, Gueguen A, Kesse-Guyot E, et al. (2012) Association between dietary patterns and depressive symptoms over time: a 10-year follow-up study of the GAZEL cohort. PLOS ONE 7, e51593.

33. Goldberg $M$ \& Zins $M$ (2015) The GAZEL cohort: 20,000 volunteers for medical research. Questionnaires. http://www.gazel.inserm.fr/en/documentation/questionnaires. html (accessed 19 January 2015).

34. Kamphuis CBM, Giskes K, de Bruijn GJ, et al. (2006) Environmental determinants of fruit and vegetable consumption among adults: a systematic review. Br J Nutr 96 , 620-635.

35. Bove CF, Sobal J \& Rauschenbach BS (2003) Food choices among newly married couples: convergence, conflict, individualism, and projects. Appetite 40, 25-41.

36. Dugravot A, Sabia S, Stringhini S, et al. (2010) Do socioeconomic factors shape weight and obesity trajectories over the transition from midlife to old age? Results from the French GAZEL cohort study. Am J Clin Nutr 92, 16-23.

37. White IR, Royston P \& Wood AM (2011) Multiple imputation using chained equations: issues and guidance for practice. Stat Med 30, 377-399.

38. Sterne JA, White IR, Carlin JB, et al. (2009) Multiple imputation for missing data in epidemiological and clinical research: potential and pitfalls. Br Med J 338, b2393.

39. Goldberg M, Chastang JF, Zins M, et al. (2006) Health problems were the strongest predictors of attrition during follow-up of the GAZEL cohort. I Clin Epidemiol 59, 1213-1221

40. Rubin DB (1987) Multiple Imputation for Nonresponse in Surveys, vol. 307. New York, NY: Wiley.

41. Akbaraly TN \& Brunner EJ (2008) Socio-demographic influences on trends of fish consumption during later adult life in the Whitehall II study. Br J Nutr 100, 1116-1127.

42. Mancino L, Todd J \& Lin B-H (2009) Separating what we eat from where: measuring the effect of food away from home on diet quality. Food Policy 34, 557-562.

43. Guthrie JF, Lin B-H \& Frazao E (2002) Role of food prepared away from home in the American diet, 1977-78 versus 1994-96: changes and consequences. J Nutr Educ Behav 34, 140-150.

44. Kjollesdal MR, Holmboe-Ottesen G \& Wandel M (2011) Frequent use of staff canteens is associated with unhealthy dietary habits and obesity in a Norwegian adult population. Public Health Nutr 14, 133-141.

45. Lachat CK, Huybregts LF, Roberfroid DA, et al. (2009) Nutritional profile of foods offered and consumed in a Belgian university canteen. Public Health Nutr 12, 122-128.

46. Roos E, Sarlio-Lähteenkorva S \& Lallukka T (2004) Having lunch at a staff canteen is associated with recommended food habits. Public Health Nutr 7, 53-61.

47. Lafay L (2009) Étude individuelle nationale des consommations alimentaires: 2006-2007 (INCA 2) (National Individual Food Intakes Survey 2006-2007 (INCA 2)). Paris: AFSSA. 
48. Ribet C, Lang T, Zins M, et al. (2001) Do cardiovascular risk factors in men depend on their spouses' occupational category? Eur J Epidemiol 17, 347-356.

49. Tai T-o \& Treas J (2013) Housework task hierarchies in 32 countries. Eur Sociol Rev 29, 780-791.

50. Guilbert P and Perrin-Escalon H (2002) Baromètre santé nutrition 2002 (Health Nutrition Barometer 2002). Paris: INPES.

51. Chauvel L \& Schröder M (2014) Generational inequalities and welfare regimes. Soc Forces 92, 1259-1283.

52. Hébel P \& Recours F (2007) Effets d'âge et de générations: Transformation du modèle alimentaire (Age and cohort effects: transformation of the food model). Cabiers de nutrition et de diététique $\mathbf{4 2}, 297-303$.
53. Castetbon K, Vernay M, Malon A, et al. (2009) Dietary intake, physical activity and nutritional status in adults: the French nutrition and health survey (ENNS, 2006-2007). Br J Nutr 102, 733-743.

54. Dubuisson C, Lioret S, Touvier M, et al. (2010) Trends in food and nutritional intakes of French adults from 1999 to 2007: results from the INCA surveys. Br J Nutr 103, 1035-1048.

55. United Nations Organization (2001) World Population Ageing 1950-2050. New York, NY: UN.

56. Lara J, Hobbs N, Moynihan PJ, et al. (2014) Effectiveness of dietary interventions among adults of retirement age: a systematic review and meta-analysis of randomized controlled trials. BMC Med 12, 60-72. 